\title{
EDITORIAL
}

\section{Clinical Prediction Rules: Challenges, Barriers, and Promise}

\author{
Emma Wallace, MB, BAO, BcH,PbD, Editorial Fellow ${ }^{1}$ \\ Michael E. Johansen, MD, MS, Associate Editor \\ 'Department of General Practice, Royal College of Surgeons in Ireland (RCSI), Dublin, Ireland
}

Ann Fam Med 2018;16:390-392. https://doi.org/10.1370/afm.2303.

$\mathrm{I}$ $\mathrm{n}$ this issue of Annals of Family Medicine, an article by Stam and colleagues focuses on the derivation and validation of a clinical prediction rule (CPR) aiming to predict which older people presenting with dizziness to their primary care physician will be more likely to have a poor prognosis. ${ }^{1}$ Dizziness is somewhat common in primary care and can be debilitating, diagnostically challenging, and difficult to treat. ${ }^{2}$ This CPR has potential to aid clinical decision making by tailoring treatment to older people at high risk of experiencing a poor outcome. Despite the great promise of CPRs, however, questions remain about whether their use will eventually lead to improvements in care delivery or improved outcomes for patients.

CPRs aim to standardize and increase the accuracy and consistency of clinicians' diagnostic and prognostic assessments and management decisions. ${ }^{3}$ With high levels of interest in CPRs (Figure 1), large numbers of CPRs have been derived and validated but comparatively very few have been evaluated in impact analysis studies. ${ }^{4}$ Examples of well-known CPRs include the prognostic CHA2DS2-VASc score, designed to predict the risk of ischemic stroke in patients with atrial fibrillation, and the diagnostic Centor score, used to identify patients with group A beta-hemolytic streptococcal throat infections who would benefit from antibiotic treatment., 5

If CPRs are to truly improve the quality of patient care then evaluation of these tools on relevant processes of care and patient outcomes is crucial. A systematic

Conflicts of interest: autbors report none.

\section{CORRESPONDING AUTHOR}

Dr Emma Wallace

Department of General Practice

Royal College of Surgeons in Ireland (RCSI)

123 Stephen's green

Dublin 2, Ireland

emmawallace@rcsi.ie review that examined CPR impact analysis studies relevant to primary care reported that implementation was restricted to a few clinical domains, mainly musculoskeletal, cardiovascular, and respiratory. ${ }^{7}$ Of 18 included studies, 10 demonstrated an improvement in primary outcome with CPR use when compared with usual care, with one-half focusing on changing physician behavior in ordering imaging for patients presenting with musculoskeletal injuries. Few studies provided data about the continued use of successful interventions. ${ }^{7}$

The issue of methodological quality has recently been addressed with the publication of 2 standardized reporting guidelines for CPR derivation and validation studies and systematic reviews of CPRs. ${ }^{8,9}$ These guidelines will have an important role to play in standardizing CPR research and in promoting robust validation of CPRs that should then be prioritized for evaluation in future impact analysis studies. However, uncertainty remains about the costs and potential unforeseen consequences of CPRs and the transportability of CPRs to other settings or health systems. ${ }^{10}$ Types of CPRs used in clinical practice varies, but use has been dictated by perceived clinical utility, familiarity, and local policy requirements. ${ }^{11}$ Prioritizing the evaluation of select clinically useful, adequately validated CPRs with proven predictive accuracy could add to this evidence base and facilitate, if appropriate, the inclusion of these select CPRs into clinical practice guidelines and potentially widespread clinical use.

Several challenges have been identified in evaluating the effectiveness of CPRs in RCTs. First, implementing CPRs is challenging on a wide scale as integration into a clinician's workflow is critical to improvement in care. Computerized clinical decisionsupport systems are effective at improving process-ofcare measures but evidence for clinical and economic outcomes remains more limited. ${ }^{12} \mathrm{~A}$ recent large-scale US study ( $\mathrm{n}=168$ primary care providers, $\mathrm{n}=40,003$ patient consultations) demonstrated the promise of 


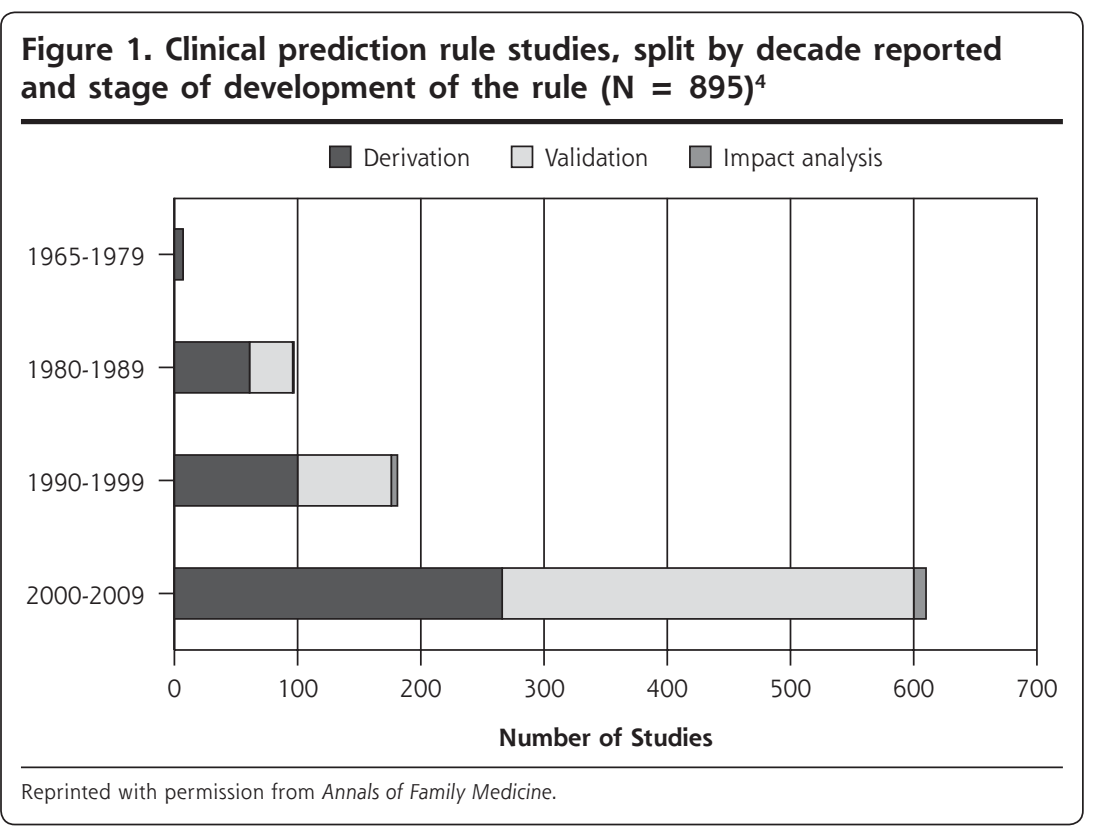

stratified as lower risk. ${ }^{19,20}$ Hundreds of citations evaluating the predictive characteristics of risk stratification CPRs such as the LACE Index Scoring Tool for Risk Assessment of Death and Readmission exist, but there is notably less evidence evaluating their effect on care. ${ }^{21}$ While it is certainly possible that efforts to design systems around "risklevels" might improve care, there is a real possibility that these systems might increase costs without related benefit, ${ }^{22}$ and could inadvertently lead to less focus on more systemic improvements. ${ }^{23}$

With increasing interest in developing and validating CPRs, it is important to consider how best to implement these tools at

CPRs by finding reduced rates of antibiotic prescribing for patients presenting with respiratory symptoms and sore throat following the integration of 2 respiratory CPRs into the electronic health record..$^{13}$ Importantly, clinicians were involved throughout the CPR process.

Other challenges important to consider include barriers to clinicians' knowledge acquisition (eg, access to the literature, interpretation of the CPR), attitudinal barriers (eg, perceived clinical utility and confidence in the CPR), and behavioral barriers including environmental factors (eg, local contextual factors), patient factors (eg, shared decision making), institutional factors (eg, degree of support locally), and fear of litigation. ${ }^{14,15}$ For example, the impact of the Canadian computed topography (CT) head rule was evaluated in a before-after study of patients $(\mathrm{n}=4,531)$ presenting with intracranial bleeding following minor head injury. ${ }^{16}$ Despite this CPR having a sensitivity rate of $100 \%$ it did not impact on CT imaging rates. In process evaluation, clinicians' reported unease with certain components of the CPR, and fear of missing this highstakes diagnosis as reasons for not adopting the CPR. ${ }^{16}$

CPRs are also increasingly advocated for risk stratification at a population level to predict utilization outcomes such as 30-day readmission or emergency hospital admissions. Financial incentives have been introduced to reduce these types of events in both the United States and the United Kingdom. Risk stratification tools for emergency hospitalization will only identify a minority of patients who are at high risk of an event, in part because of the modest predictive accuracy of these tools ${ }^{17,18}$ and because, in absolute terms, most emergency admissions occur in patients the point of clinical care to improve processes of care, patient outcomes, and system efficiency. Selecting CPRs in relevant clinical domains with proven predictive accuracy for impact analysis is essential. However, the impact of CPRs such as clinicians' beliefs, local contextual factors and how best to integrate the CPR into different clinical workflows. Without due consideration of these issues, the great promise of CPRs to aid clinical decision making may not be realized.

To read or post commentaries in response to this article, see it online at http://www.AnnFamMed.org/content/16/5/390.

Submitted July 31, 2018; submitted, revised, August 14, 2018; accepted August 14, 2018.

Key words: decision support techniques; risk

\section{References}

1. Stam H, Maarsingh OR, Heymans MW, van Weert HC, van der Wouden JC, van der Horst HE. Predicting an unfavorable course of dizziness in older patients. Ann Fam Med. 2018;16(5):428-435.

2. Bösner S, Schwarm S, Grevenrath P, et al. Prevalence, aetiologies and prognosis of the symptom dizziness in primary care - a systematic review. BMC Fam Pract. 2018;19:33.

3. McGinn TG, Guyatt GH, Wyer PC, Naylor CD, Stiell IG, Richardson WS; Evidence-Based Medicine Working Group. Users' guides to the medical literature: XXII: how to use articles about clinical decision rules. JAMA. 2000;284(1):79-84.

4. Keogh C, Wallace E, O'Brien KK, et al. Developing an international register of clinical prediction rules for use in primary care: a descriptive analysis. Ann Fam Med. 2014;12(4):359-366.

5. Lip GY, Nieuwlaat R, Pisters R, Lane DA, Crijns HJ. Refining clinical risk stratification for predicting stroke and thromboembolism in atrial fibrillation using a novel risk factor-based approach: the euro heart survey on atrial fibrillation. Chest. 2010;137(2):263-272. it is also critically important to anticipate barriers to 
6. Centor RM, Witherspoon JM, Dalton HP, et al. The diagnosis of strep throat in adults in the emergency room. Med Decis Making. 1981;1(3):239-246.

7. Wallace E, Uijen MJ, Clyne B, et al. Impact analysis studies of clinical prediction rules relevant to primary care: a systematic review. BMJ Open. 2016;6(3):e009957.

8. Moons KG, de Groot JA, Bouwmeester W, et al. Critical appraisal and data extraction for systematic reviews of prediction modelling studies: the CHARMS checklist. PLoS Med. 2014;11(10):e1001744.

9. Collins GS, Reitsma JB, Altman DG, Moons KG. Transparent reporting of a multivariable prediction model for Individual Prognosis or Diagnosis (TRIPOD): the TRIPOD statement. J Clin Epidemiol. 2015; 68(2):134-143

10. McDonald R, Roland M. Pay for performance in primary care in England and California: comparison of unintended consequences. Ann Fam Med. 2009;7(2):121-127

11. Plüddemann A, Wallace $E$, Bankhead C, et al. Clinical prediction rules in practice: review of clinical guidelines and survey of GPs. $\mathrm{Br} J$ Gen Pract. 2014;64(621):e233-e242.

12. Bright TJ, Wong A, Dhurjati R, et al. Effect of clinical decisionsupport systems: a systematic review. Ann Intern Med. 2012;157(1): 29-43.

13. McGinn TG, McCullagh L, Kannry J, et al. Efficacy of an evidencebased clinical decision support in primary care practices: a randomized clinical trial. JAMA Intern Med. 2013;173(17):1584-1591.

14. Lang ES, Wyer PC, Haynes RB. Knowledge translation: closing the evidence-to-practice gap. Ann Emerg Med. 2007;49(3):355-363.

15. Keogh C, Fahey T. Guest Editorial. Clinical prediction rules in primary care: what can be done to maximise their implementation? http://clinicalevidence.bmj.com/downloads/05-10-10.pdf. Published May 10, 2010.
16. Stiell IG, Clement CM, Grimshaw JM, et al. A prospective clusterrandomized trial to implement the Canadian $C T$ Head Rule in emergency departments. CMAJ. 2010;182(14):1527-1532.

17. Kansagara D, Englander H, Salanitro A, et al. Risk prediction models for hospital readmission: a systematic review. JAMA. 2011; 306(15):1688-1698.

18. Wallace E, Stuart E, Vaughan N, Bennett K, Fahey T, Smith SM. Risk prediction models to predict emergency hospital admission in community-dwelling adults: a systematic review. Med Care. 2014; 52(8):751-765.

19. Wallace E, Smith SM, Fahey T, Roland M. Reducing emergency admissions through community based interventions. BMJ. 2016;352: h6817.

20. NHS England. Using Case Finding and Risk Stratification. https://www. england.nhs.uk/wp-content/uploads/2015/01/2015-01-20-CFRSv0.14-FINAL.pdf. Published Jan 2015.

21. Dhalla IA, O'Brien T, Morra D, et al. Effect of a postdischarge virtual ward on readmission or death for high-risk patients: a randomized clinical trial. JAMA. 2014;312(13):1305-1312.

22. Snooks H, Bailey-Jones K, Burge-Jones D, et al. Predictive risk stratification model: a randomised stepped-wedge trial in primary care (PRISMATIC). Health Serv Deliv Res. 2018;6(1).

23. McWilliams JM, Chernew ME, Landon BE. Medicare ACO Program savings not tied to preventable hospitalizations or concentrated among high-risk patients. Health Aff (Millwood). 2017;36(12): 2085-2093.

\section{Get the Annals of Family Medicine by E-mail}

Make sure you see every new issue

while it's fresh; have the table of

contents sent to you by e-mail for

easy access to articles of interest.

Don't miss important research.

Request the e-mail table of contents at

http://www2.highroadsolution.com/

aafp_annals_preference_center/search.aspx

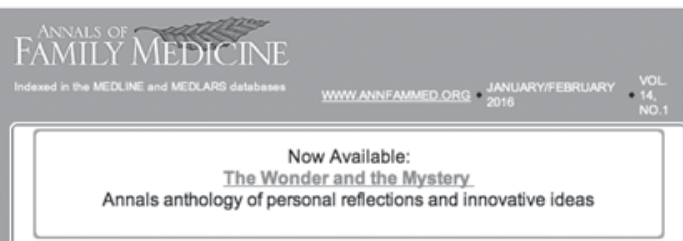

The All text of the journal is avallable online at hthp / thumw annfammed, org and through various MEDLINE and MEDLARS, Sdience Citation Index Expanded, Current Contents Clinical Medicine, PSyclNFO, EMBASE, and CINHAL database:

EDirÓRIALS

Kunt C. Stange Size Matters

Achieving PCMH Status May Not Be Meaningtul for Small Practices

The Paradox of Size: How Small, Indeneendent Practices Can Thrive in Valve-Based Care Farad Mostashar

ORIGINAL RESEARCH

Solo and Small Practices: A Vital, Diverse Part of Primary Cary

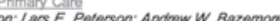
Family physicians in solo and small practices outnumber those in larger practices.

Large Indegandent Primary Care Medical Groups

have the potential to make primary care attractive to physicians

Primary Care Physician Panel Size and Quality of Care: A Pooviation-Based Study in Ontario.

Cimone Dahrouge; Wwilam Hogg: Jaime Younger, Elizabeth Muggah; Grant Russell; Richard H 